\title{
Hibrit olarak alüminyum ve demir elektrotlar kullanarak elektrokoagulasyon prosesleri ile sulu çözeltilerden salisilik asit gideriminin araştırılması
}

\section{Removal of salicylic acid from aqueous solutions by electrocoagulation processes using hybrid electrode}

\author{
Fuat Özyonar 1(i), Ömür Gökkuş²* (iD) \\ ${ }^{I}$ Sivas Cumhuriyet Üniversitesi, Çevre Mühendisliği Bölümü, 58140, Sivas, Türkiye \\ ${ }^{2}$ Erciyes Üniversitesi, Çevre Mühendisliği Bölümü,38039, Kayseri, Türkiye
}

\section{Özet}

$\mathrm{Bu}$ çalışmada, elektrokoagulasyon prosesiyle sulu çözeltilerden önemli ve yaygın olarak kullanılan bir mikrokirletici sınıfına giren ve ilaç etken maddesi olan sulu çözeltilerden salisilik asittin giderimi araştırılmıştır. Elektrokimyasal aritma proseslerinde yaygin olarak kullanılan aritma prosesleri elektrokoagulasyon ve elektroflotasyon teknikleridir. Elektrokimyasal proseslerde proses verimini belirleyen en temel değişkenlerden birisi, kullanılan elektrot materyalinin cinsidir. $\mathrm{Bu}$ çalışmada elektrokoagulasyon prosesiyle hibrit olarak demir ve alüminyum elektrot kombinasyonu kullanılmıştır. Elektrokoagulasyon prosesine etki eden parametrelerden akım yoğunluğu, başlangıç $\mathrm{pH}$, elektroliz süresi ve elektriksel iletkenliğin etkisi salisilik asit giderim verimi üzerine etkisi araştırılmıştır. Bu amaçla elektrokoagulasyon (EC) prosesinde akım yoğunluğu $20 \mathrm{~A} / \mathrm{m}^{2}$ ve $100 \mathrm{~A} / \mathrm{m}^{2}$ değerinde, başlangıç pH 5-8, Elektroliz süresi 2-50 dakika, elektriksel iletkenlik $250-1000 \mu \mathrm{s} / \mathrm{cm}$ aralığında ve elektrotlar monopolar paralel (MP-P) bağlantı türünde bağlanarak sulu çözeltilerden salisilik asit giderme verimleri incelenmiştir. En yüksek giderme verimi $\mathrm{pH} 6$, Akım yoğunluğu $80 \mathrm{~A} / \mathrm{m}^{2}$, çözelti iletkenliği $750 \mu \mathrm{s} / \mathrm{cm}$, ve Elektroliz süresi 40 dakika olarak elde edilmiştir. Bu işletme şartlarında \%91.4 Salisilik asit giderimi, $0.8 \mathrm{~kg} / \mathrm{m} 3$ çamur oluşumu ve $1.34 \$ / \mathrm{m}^{3}$ işletme maliyeti bulunmuştur.

Anahtar kelimeler: Hibrit elektrot, Elektrokoagulasyon, Salisilik asit, Mikrokirletici

\section{Giriş}

Her geçen gün şehirlerimizde içme, kullanma ve endüstriyel olarak suya olan ihtiyaç giderek artmaktadır. Mevcut kullanılabilir su kaynaklarının hızlı bir şekilde tükenmesi ve doğal ve antropojenik olarak kirlenmeye uğraması bu kaynaklardan su temininde önemli bir sorun oluşturmaktadır.

İnsan, hayvan ve tarım sağlığının korunması için ilaç endüstrisi hızlı bir şekilde gelişmekte ve değişik türde ilaçlar tedavi amaçlı veya ürün miktar ve kalitesinin arttırmak amaciyla kullanılmaktadır. İnsan ve havyan sağlığ korumak, hastalıkların teşhisi, tedavisi ve önlenmesi amacıyla kullanılmakta olan birçok ilaç, canlı metabolizmasinda tamamiyla metabolize olmamakta ya

\section{Abstract}

In this study, salicylic acid, an important and widely used micropollutant in the pharmacy sector, removal by electrocoagulation process was investigated. Electrocoagulation and electroflotation processes are commonly used techniques in electrochemical treatment. The type of electrode material employing in electrochemical processes is one of the basic variables which determining the process performance. In the experiments, iron and aluminum plates were employed as a hybrid electrode combination in the electrocoagulation process. The effect of current density, initial $\mathrm{pH}$, electrolysis time, and electrical conductivity were investigated. For this purpose, the current density was 20 $\mathrm{A} / \mathrm{m}^{2}$ and $100 \mathrm{~A} / \mathrm{m}^{2}$, initial $\mathrm{pH} \mathrm{5-8,} \mathrm{electrolysis} \mathrm{time} \mathrm{2-50}$ min electrical conductivity $250-1000 \mu \mathrm{s} / \mathrm{cm}$ range and electrode connection type monopolar parallel (MP-P) salicylic acid removal efficiencies from aqueous solutions were investigated during the experimental studies. The best removal results were obtained at $\mathrm{pH} 6$ with a current density of $80 \mathrm{~A} / \mathrm{m}^{2}$, solution conductivity of $750 \mu \mathrm{s} / \mathrm{cm}$, and $40 \mathrm{~min}$ of electrolysis time. In these operation conditions, operation cost, amount of sludge, and removal efficiency of salicylic acid were determined as $1.34 \$ / \mathrm{m}^{3}, 0.8 \mathrm{~kg} / \mathrm{m}^{3}$, and $91.4 \%$, respectively.

Keywords: Hybrid electrode, Electrocoagulation, Salicylic acid, Micropollutant.

olduğu gibi ya da bir başka ürüne dönüşerek vücuttan idrar, dışkı ve ter ile atılmaktadır. İlaç aktif maddeleri atıksulara insan dışkılarından ve hastane atıksularından ulaşabilmekte, ayrıca atıksu arıtma sisteminde arıtılmadan deşarj edilmektedir. Bu konu ile yapılan çalıșmalar, su kaynaklarına ve besin zincirine değişik taşınımlar ile karışan ilaç aktif maddelerinin ve metabolitlerinin ekosistem ve insan sağlığ1 için gerçek bir tehdit oluşturduğunu göstermektedir [1].

İlaç aktif maddeleri canlıların yapılarına girdikten sonra hedef noktaya ulaşması için enzimlere karşı ve midenin asidik pH'sına karşı dayanıklı olarak üretilmektedir. Bu nedenle ilaç etken/kalıntı maddeleri biyolojik olarak birikerek sucul ve karasal ortamda ekosisteme katılarak

\footnotetext{
* Sorumlu yazar / Corresponding author, e-posta / e-mail: omurgokkus @ erciyes.edu.tr (Ö. Gökkuş)

Geliş / Recieved: 17.12.2020 Kabul/ Accepted: 09.04.2021 Yayımlanma/Published: 27.07.2021

doi: $10.28948 /$ ngmuh. 842616
} 
olumsuz etkilere neden olmaktadırlar. Aslında sürekli ve tekrar tekrar çevreye katılan ilaç kalıntı maddeleri ciddi ve önemli bir çevre kirliliği sorunu yaratarak karşımıza çıkmaktadır. $\mathrm{Bu}$ maddelerin kalıcı olduğu düşünülürse, tamamıla parçalanmaması ya da giderilmemesi nedeniyle yerine yenisi gelerek her zaman verildiği ortamda birikmektedir. Avrupa Birliği ülkelerinde insanlar için üretilen yaklaşık 3000 farklı ilaç; ağrı kesici ve antienflamatuvar ilaçlar, kontraseptivler (gebelik önleyici ilaçlar), antibiyotikler, beta-blokerler, nöroaktif bileşikler ve birçok başka ilaç türü olarak kullanılmaktadır. Bunlar arasında da antibiyotikler ve antienflamatuvar ilaçlar sayılabilir [2, 3].

İngiltere, Almanya ve Avustralya'da sık kullanılan ilaçların tüketim miktarı ise senede yüzlerce ton seviyesindedir [3]. Ülkemizde 2019 yılı verilerine göre ilaç tüketim miktarları Şekil 1'de verilmiştir. 2019 yılı verilerine göre değerlendirme yapıldığında nüfus artışı da göz önüne alınacak olursa sayıların zamana bağlı artışı dikkat çekicidir Ülkemizde ilaç miktarı kutu ve değer olarak Eylül 2019 tarihi itibari ile 2.3 milyar kutu ölçeğinde ve 37.8 milyar TL ölçeğinde bir hacme ulaşmıştır [4].

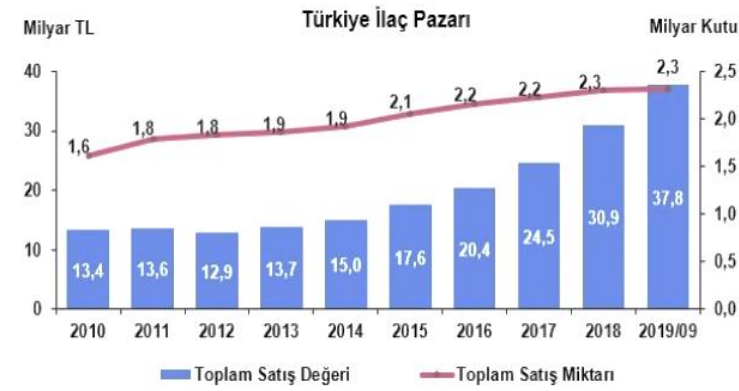

Şekil 1. Türkiye'de yıllık ilaç pazarı [4].

Şekil 2'de son bir yılda tedavi gruplarına göre en çok tüketilen ilaçların \%11 pay ile antibiyotikler ve antiromatizmal ilaçlar olduğu görülmektedir [4].

Ülkemizde en çok kullanılan ilaç grupları başında antibiyotikler, antieflamatuvar ve antidiyabetik ilaçlar gelmektedir. Ülkemizde kullanım miktarının fazlalığı ve reçetesiz ilaç satımına bağlı olarak ilaç kalıntı maddelerinin özellikle alıcı ortamlarda olumsuz etkide bulunacağı açıktır

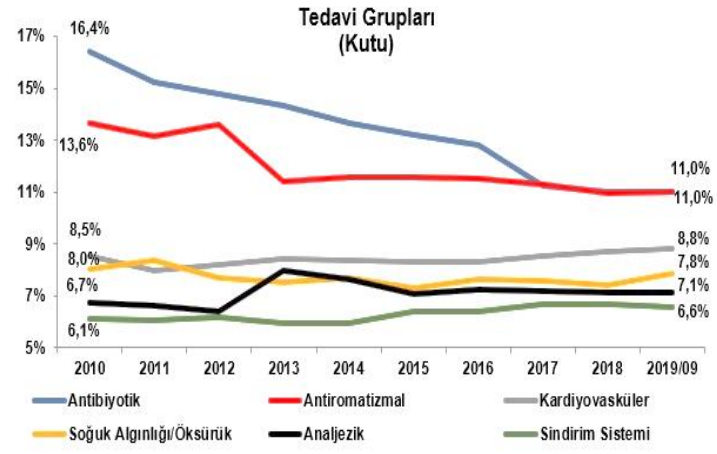

Şekil 2. Türkiye'de çeşitli yıllarda tüketilen ilaçların tedavi gruplarına göre dağılımı [4].
Son yıllarda yapılan çalışmalarda atıksularda ve arıtma tesisi çıkışlarında, yüzeysel sularda ve yeraltı sularında ilaç kalıntı maddelerine rastlanılmıştır [5-7]. Söz konusu bu kalıntı maddelerin bulunması insanlarda cinsiyet bozukluğuna, üreme kapasitesinin düşüşü gibi çeşitli sorunlara yol açtığı gibi sucul canlılar açısında da akut veya toksik etkiye sebep olmaktadır. Ayrıca söz konusu bu kimyasal maddelere yapılan bazı araştırmalarda içme sularında da rastlanmıştır. Mevcut atıksu arıtma tesislerinde bu maddelerin gideriminin araştırılması bazı araştırmacılar tarafından yapılmıştır. Bazı ilaç kalıntı maddeleri giderimi yüksek iken bazılarının giderim verimi ise düşük kalmıştır. Özellikle atıksuda bu ilaç etken maddelerinin bir arada bulunması, toplam etkilerinde bir artışa (sinerjik etki) neden olacağı yapılan çalışmalarla kanıtlanmıştır. Bununla klasik arıtma sistemleri ile bu mikrokirleticilerin arıtılması oldukça zor ve maliyetlidir. Bu kalıntı maddeler sahip oldukları kimyasal özellik nedeniyle biyolojik olarak parçalanmaları oldukça zor ve toksiktirler. Bu sebeple farklı alternatif arıtma yöntemleri ile bu kimyasalları içeren suların arıtılması oldukça önemlidir. Şekil 3'de arıtma tesislerinde bazı mikrokirleticilerin giderim verimleri verilmektedir

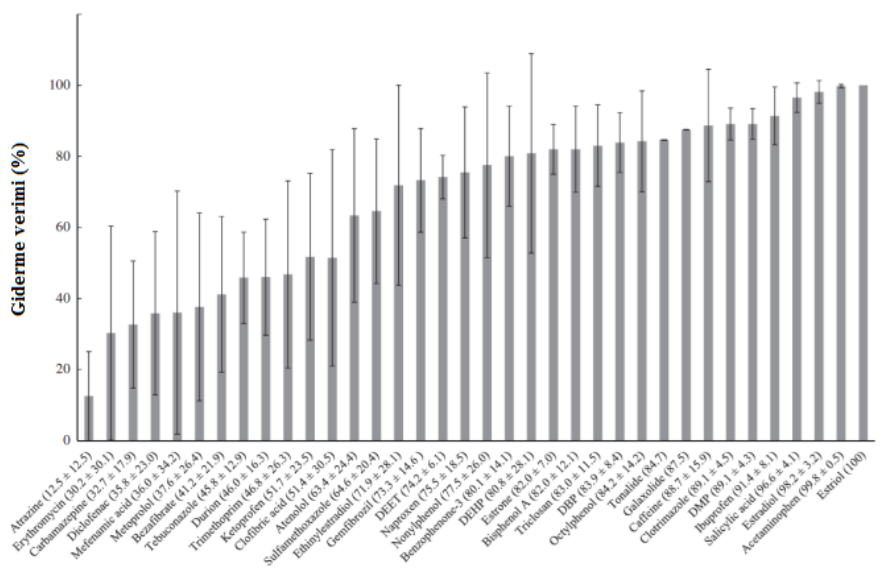

Şekil 3. Bazı mikrokirleticilerin atıksu arıtma tesislerinde giderilme verimleri [8].

Şekil 3'de görüldüğü gibi bazı mikrokirleticilerin gideriminde atıksu arıtma tesislerinde yüksek giderim verimleri sağlanabilirken bazılarında ise giderim verimleri yetersiz kalmaktadır. Özellikle düşük giderme verimleri ilaç etken maddelerinin sebep olduğu mikrokirleticilerden kaynaklanmaktadır. Bu nedenle özellikle ilaç kalıntıları için suların farklı arıtma yöntemleri denenerek arıtılabilirliği ile ilgili çalışmalar oldukça önemlidir.

Çeşitli arıtma yöntemleri ile ilaç kalıntı maddelerinin sulardan giderimi araştırılmıştır, örneğin ozonlama [9], fotoFenton [10], foto-elektrokatalitik bozundurma [11], iyon değiştirme [12], adsorbsiyon [13] gibi proseslerle arıtılabilirlilik çalışılmıştır. Özellikle adsorbsiyon prosesinin düşük derişimli kalıntıların gideriminde etkili verimler alındığı saptanmıştır [14].

Son y1llarda elektrokimyasal prosesler ile farklı özellikteki atıksuların arıtımına yönelik çalışmalar hız kazanmış ve çoğunda başarılı sonuçlar elde edilmiştir. Elektrokimyasal atıksu arıtım proseslerini birbirinden ayıran 
en temel özellik kirleticilerin giderilmesini sağlayan elektrokimyasal prosesin şekli ve yapısıdır. Bu durumu belirleyen kullanılan elektrotların özellikleridir. Elektrokimyasal atıksu arıtımında en çok elektrooksidasyon, elektroflotasyon ve elektrokoagulasyon prosesleri kullanılmaktadır. Bu prosesler birlikte veya ayrı olarak bir sistem içerisinde olabilir. Atıksuda bulunan kirleticiler bu prosesler ile okside, adsorbe veya reaktör yüzeyinde birikerek ayırımı sağlanmaktadır. Temel olarak elektrokoagulasyon reaktör sisteminde elektroliz esnasında gerçekleşen mekanizmalar Şekil 4'de verilmektedir.

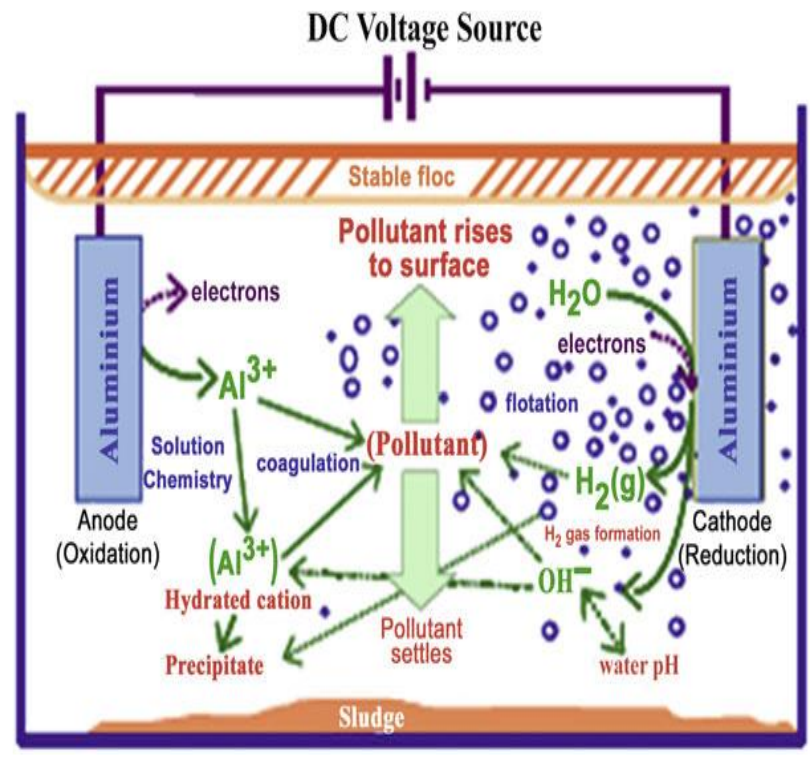

Şekil 4. Elektrokoagulasyon prosesinde gerçekleşen reaksiyonlar [15].

Elektrokoagulasyon prosesinde, anot olarak çözünen demir veya alüminyum elektrotlar kullanılması halinde bu elektrotlar çözünerek çözeltiye $\mathrm{Al}^{3+}$ ve $\mathrm{Fe}^{2+}, \mathrm{Fe}^{3+}$ iyonları vermekte olup, bu iyonlar sudaki hidroksil iyonları ile birleşerek çok az çözünen $\mathrm{Al}(\mathrm{OH})_{3}, \mathrm{Fe}(\mathrm{OH})_{2}$ ve $\mathrm{Fe}(\mathrm{OH})_{3}$ gibi metal hidroksitler oluşturmaktadır. Elektrokoagulasyon anında oluşan metal hidroksit partiküllerinin adsorbsiyon özellikleri çok yüksektir.

Koagüle edilen partiküller atıksularda bulunan mikro koloidal partikülleri ve iyonları kendilerine doğru çekerek adsorbe etmektedir. Oluşan yumaklar çökelmekte ve elektroflotasyonda oluşan gazlar yardımıyla su yüzeyine kaldırılabilmektedir. Bu yöntem renk, KOİ, toplam organik karbon (TOK), askıda madde (AKM) ve ağır metallerin atıksulardan giderilmesinde kullanılmaktadır [16].

$\mathrm{Bu}$ çalışmada, salisilik asidin sulu çözeltiden gidermek amaciyla Al-Fe-Fe-Al (Anot-Katot-Anot-Katot) elektrotlarının ve bağlantılarının kullanıldığı elektrokoagulasyon prosesine etki eden parametrelerden başlangıç $\mathrm{pH}$, akım yoğunluğu, elektroliz süresi ve elektriksel etkisi araştırılmıştır. Elektrokoagulasyon prosesinde optimum şartları belirlemek için salisilik asit ve KOİ parametreleri incelenmiştir.

\section{Materyal ve metot}

\subsection{Malzeme}

Çalışmada moleküler ağırlığı $138.121 \mathrm{~g} / \mathrm{mol}$ olan SA (salisilik asit) saf suya ilave edilerek $100 \mathrm{mg} / \mathrm{L}$ konsantrasyonda SA içeren sulu çözeltiler hazırlanmıştır. SA içeren bu sulu çözeltiler optimum çalışma koşullarını belirlemek için farklı deneysel koşullar uygulanarak EC çalışmaları yapılmıştır. Deneysel çalışmalar esnasında SA gideriminin izleneceği dalga boyunu tespit etmek üzere UV bölgede (200-400 $\mathrm{nm}$ ) arasında yapılan absorbans taraması ile maksimum absorbans veren dalga boyunun $296 \mathrm{~nm}$ olduğu belirlenmiştir. Ayrıca SA için kimyasal yapı çeşitli fizikokimyasal özellikler Şekil 5'de verilmektedir.

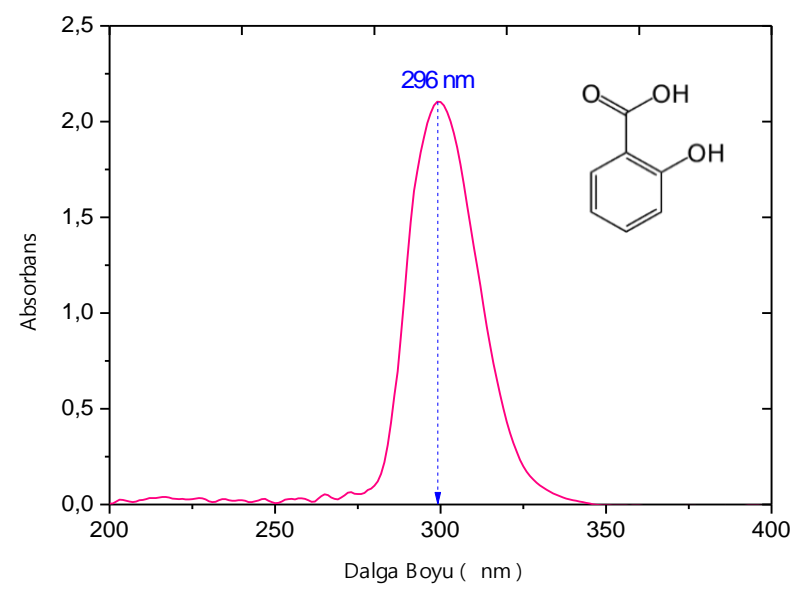

Şekil 5. Salisilik asit kimyasal özellikleri ve yapısı.

EC deneysel çalışmaları, Özyonar (2020) ve ark. tarafından daha önceki çalışmalarda detaylı olarak verilen elektrokimyasal çalışma düzeneğinde yürütülmüştür [17]. EC için her bir deneyde elektrotlar, elektrokoagulasyon reaktörüne yerleştirildikten sonra reaktör içerisinde 1000 ml'lik çözelti hacmi ile deneysel çalışmalar yürütülmüştür. Güç kaynağı üzerinde istenen akım ve voltaj ayarlaması yapıldıktan sonra elektrokoagulasyon işlemine başlanmıştır.

\subsection{Yöntem ve işletme maliyeti hesaplanması}

Elektrokoagulasyon (EC) deneyleri Şekil 6'da sunulan deney düzeneğinde gerçekleştirilmiştir. Akım ve voltaj kontrollü, dijital bir güç kaynağı (GPC 6030D) ile sağlanmıştır. Karıştırma manyetik bir karıştırıcı ile gerçekleştirilmiştir. EC deneylerinde kullanılan 100 x $100 \mathrm{x}$ $130 \mathrm{~mm}$ boyutlarındaki reaktör çift cidarlı olup, plexiglass'dan yapılmıştır. Reaktör ceketli olarak tasarlanıp reaksiyon sıcaklığının $25{ }^{\circ} \mathrm{C}$ 'de sabit kalması için sürekli su sirkülasyonu sağlanmıştır. Reaktörde her bir deneyde 1000 $\mathrm{ml}$ su numunesi kullanılmıştır. Reaktörde farklı bağlantı modlarında 4 elektrot kullanılmıştır. Elektrotlar $20 \mathrm{~mm}$ aralıklarla yerleştirilmiş ve tamamen elektrolite batırılmış durumdadır. Elektrot materyali olarak 50 × 70 × $2 \mathrm{~mm}$ boyutlarında, $210 \mathrm{~cm}^{2}$ aktif yüzey alanına sahip $\mathrm{Al}$ ve $\mathrm{Fe}$ plakalar kullanılmıştır. Kullanılan alüminyum plakalar, Al: \% 99.53; Si: \% 0.12; Fe: \% 0.25 içeriğine, demir plakalar ise $\% 99.32$ Fe içeriğine sahiptir 


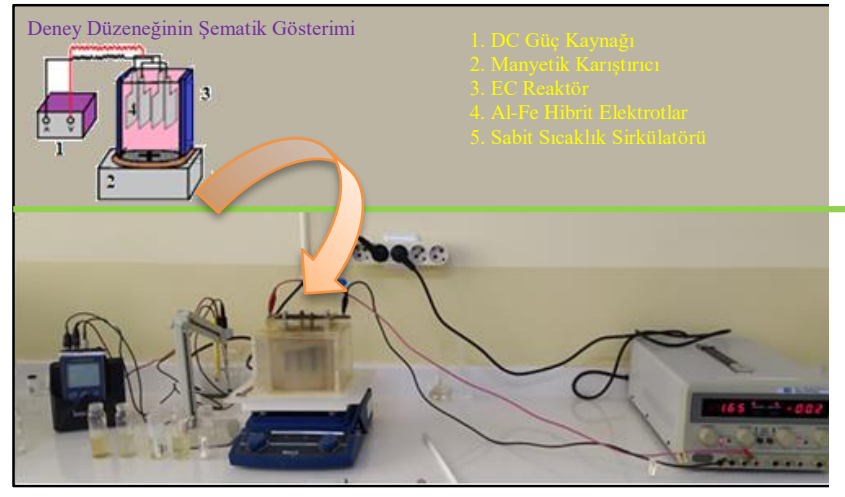

Şekil 6. Deneysel çalışmada kullanılan elektrokoagulasyon deney düzeneğinin görünüşü.

EC işleminden sonra çözelti filtre edilmiş ve gerekli analizler yapılmıştır. EC işlemi sonunda oluşan çamur kuru ağırlık olarak tespit edilmiştir. EC sonunda tüm çözelti ve çamur karışımı oda sıcaklığında kaba filtre kâğıdından süzülerek ağırlığı hesaplanmıştır. Daha sonra etüvde $105^{\circ} \mathrm{C}$ 'de kurutulup bekletildikten ve sabit tartıma getirildikten sonra çamur miktarları belirlenmiştir [2].

İşletme maliyeti enerji tüketimi ve elektrot tüketimi dikkate alınarak hesaplanmıştır. Elektrot maliyeti sadece elektrokoagulasyon prosesinde kullanilan $\mathrm{Fe}$ ve $\mathrm{Al}$ elektrotlar için dikkate alınmış̧ır (demir elektrot için 0.5 $\$ / \mathrm{kg}$, alüminyum elektrot için $1.7 \$(\mathrm{~kg})$. İşletme maliyeti $\$ / \mathrm{m}^{3}$ arıtılmış atıksu olarak hesaplanmıştır [18].

$$
\begin{aligned}
& \mathrm{C}_{\text {enerji }}: \frac{V \times 1 \times t_{E C}}{\vartheta} \\
& C_{\text {elektrot }}: \frac{i \times t_{E C \times} M w}{z \times F \times \vartheta}
\end{aligned}
$$

Burada $\mathrm{C}_{\text {enerji }}\left(\mathrm{m}^{3}\right.$ arıtılan su başına $\left.\mathrm{kWh}\right)$ ve $\mathrm{C}_{\text {elektrot }}\left(\mathrm{m}^{3}\right.$ arıtılan su başına $\mathrm{kg}$ ) enerji ve elektrot tüketimlerini ifade etmektedir. Ayrica $V$ uygulanan potansiyel değerini, tec elektroliz süresini (dakika veya saat), $i$ uygulanan akım şiddetini (Amper), $\vartheta$ sivi hacmini $\left(\mathrm{m}^{3}\right), M_{w}$ demir veya alüminyumun mol kütlesini $\left(\mathrm{g} / \mathrm{m}^{3}\right.$ cinsinden $), F$ Faraday sabitini $(96485 \mathrm{C} / \mathrm{mol}), z$ ise metal atomu başına transfer edilen elektron sayısını (Fe: 2, Al: 3) ifade etmektedir [17].

\section{Bulgular ve tartışma}

Al-Fe-Fe-Al (anot-katot-anot-katot) elektrotlarının kullanıldığı elektrokoagulasyon çalışmalarında, başlangıç pH 5-7 aralığında, akım yoğunluğu $20-100 \mathrm{~A} / \mathrm{m}^{2}$ aralığında, Salisilik asit konsantrasyonu $100 \mathrm{mg} / \mathrm{L}$, elektriksel iletkenlik $250-1000 \mu \mathrm{s} / \mathrm{cm}$ ve elektroliz süresi 2-20 dakika aralı̆ğında, elektrot bağlantı türü monopolar paralel (MP-P) bağlantı türü uygulanarak sulu çözeltiden SA giderimi araştırılmıştır.

\subsection{Salisilik asit giderimi üzerine $p H$ 'ın etkisi}

Elektrokoagulasyon prosesinde önemli işletme parametrelerinden biriside çözeltinin elektroliz öncesi $\mathrm{pH}$ değeridir. EC prosesinde $\mathrm{pH}$ çözelti içerisinde oluşan metal hidroksit formunun türlerini belirlemekle birlikte oluşacak kabarcık formunu ve boyutunu etkilemektedir. Dolayısıyla her atıksu veya kirlenmiş su için elektrokimyasal arıtmada en yüksek giderme veriminin elde edileceği $\mathrm{pH}$ değeri belirlenmelidir. Yapılan bu çalışmada $\mathrm{pH}$ 5-8 aralığında değiştirilerek incelenmiştir. Şekil 7'de görüldüğü gibi en yüksek giderme verimi pH 6'da elde edilmiştir.

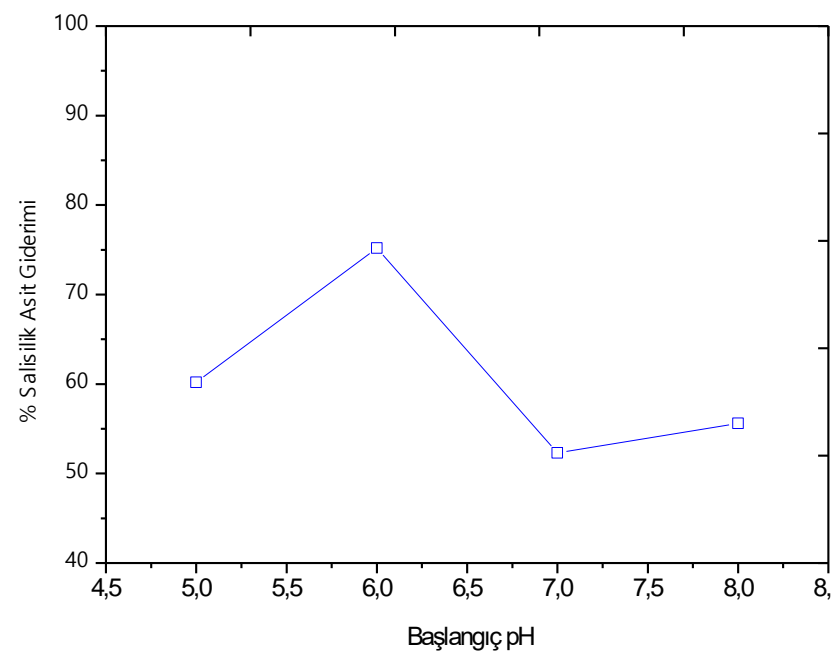

Şekil 7. Farklı $\mathrm{pH}$ değerlerinde SA giderme verimi. (60 $\mathrm{A} / \mathrm{m}^{2}$ akım Yoğunluğunda, SA konsantrasyonu $100 \mathrm{mg} / \mathrm{L}$, Elektriksel iletkenlik $750 \mu \mathrm{s} / \mathrm{cm}$, Elektroliz süresi 20 dakika, Al-Fe-Fe-Al, MP-P bağlantı türünde).

\subsection{Salisilik asit giderimi üzerine akım yoğunluğunun etkisi}

Elektrokoagulasyon prosesinde akım yoğunluğu kontrol edilebilen en önemli işletme parametrelerinden birisidir. Elektrokimyasal proseslerde akım yoğunluğu oluşan koagulant miktarını, kabarcık üretim hızını ve boyutunu belirlediği için prosesin verimini önemli derecede değiştirmektedir. $\mathrm{Bu}$ amaçla, akım yoğunluğunun $\mathrm{SA}$ giderimi üzerine etkisini incelemek için akım yoğunluğu 20$100 \mathrm{~A} / \mathrm{m}^{2}$ aralığında değiştirilerek uygulanmıştır. Şekil 8 'de görüldüğü gibi en yüksek giderme verimi $80 \mathrm{~A} / \mathrm{m}^{2}$ akım yoğunluğunda elde edilmiştir.

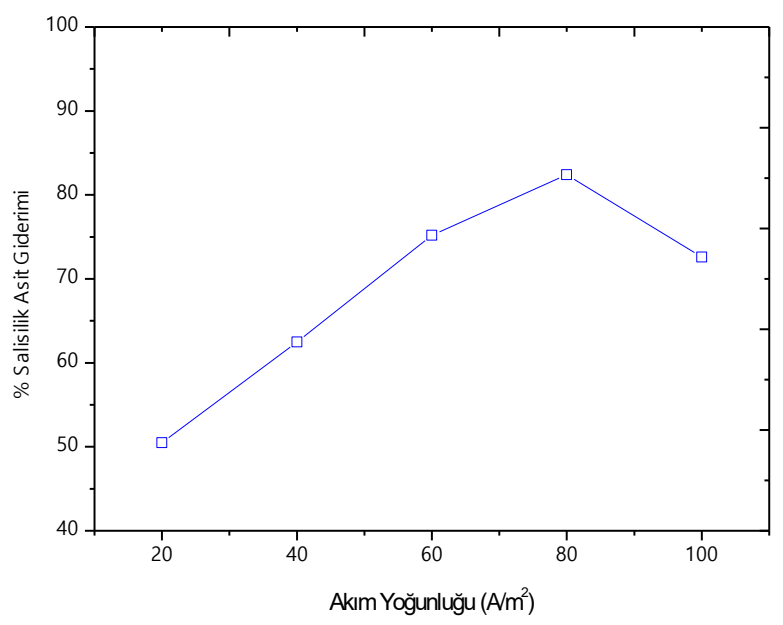

Şekil 8. Farklı Akım yoğunluğu değerlerinde SA giderme verimi. (Başlangıç pH 6, SA konsantrasyonu $100 \mathrm{mg} / \mathrm{L}$, Elektriksel iletkenlik $750 \mu \mathrm{s} / \mathrm{cm}$, Elektroliz süresi 20 dakika, Al-Fe-Fe-Al, MP-P bağlantı türünde). 
Şekil 8'den görüleceği üzere akım yoğunluğunun 20 $\mathrm{A} / \mathrm{m}^{2}$ değerinden $80 \mathrm{~A} / \mathrm{m}^{2}$ değerine arttırılması ile birlikte salisilik asit giderim verimi $\% 50.5$ 'den $\% 82.4$ 'e artmıştır. Salisilik asit giderim veriminde meydana gelen bu artış, akım yoğunluğunun arttırılması ile Faraday yasasına göre anotta çözünen metal iyonlarının artışı ile açıklanabilmektedir [19]. Ancak akım yoğunluğunun $80 \mathrm{~A} / \mathrm{m}^{2}$ değerinin üzerine çıkarılması salisilik gideriminde bir miktar azalışa neden olmuştur. $\mathrm{Bu}$ durumun olası sebebinin yüksek akım yoğunluğu değerlerinde Reaksiyon 1 ve Reaksiyon 2 gereğince katotta meydana gelen aşırı hidrojen gazı ve $\mathrm{OH}^{-}$ iyonlarına bağlı $\mathrm{pH}$ artışı olduğu düşünülmektedir [20,21].

$$
\text { Anot Reaksiyonu : } \mathrm{Al}_{(\mathrm{s})} \rightarrow \mathrm{Al}^{+3}{ }_{(\mathrm{aq})}+3 \mathrm{e}^{-}
$$

Katot Reaksiyonu: $3 \mathrm{H}_{2} \mathrm{O}_{(\mathrm{l})}+3 \mathrm{e}^{-} \rightarrow 3 / 2 \mathrm{H}_{2(\mathrm{~g})}+3 \mathrm{OH}^{-}(\mathrm{aq})(2)$

\subsection{Salisilik asit giderimi üzerine iletkenliğin etkisi}

Elektriksel iletkenlik elektrokoagulasyon prosesi üzerine etkisi hem maliyet hem de verim açısından etkisi olan diğer bir işletme parametresidir. Elektriksel iletkenlik çözeltinin iyonik gücü ile ilgilidir ve enerji tüketimi üzerinde değişikliğe sebebiyet verecek bir etkiye sahiptir.

Kullanılan elektrolit çözeltisi iletkenliği artırarak direnç düşüşüne sebep olur ve elektrik tüketimini azaltır. $\mathrm{Bu}$ çalışmada bu etkinin SA giderme verimini üzerine olan etkisini araştırmak amacıyla $\mathrm{NaCl}$ kullanılarak iletkenlik 250-1000 $\mu \mathrm{s} / \mathrm{cm} \quad$ aralığında değiştirilerek elektrokoagulasyon çalışmaları yürütülmüş̧ür. Şekil 9 'da görüldüğ ü gibi en yüksek giderme verimi \% 82.4 ile 750 $\mu \mathrm{s} / \mathrm{cm}$ elektriksel iletkenlik değerinde elde edilmiştir.

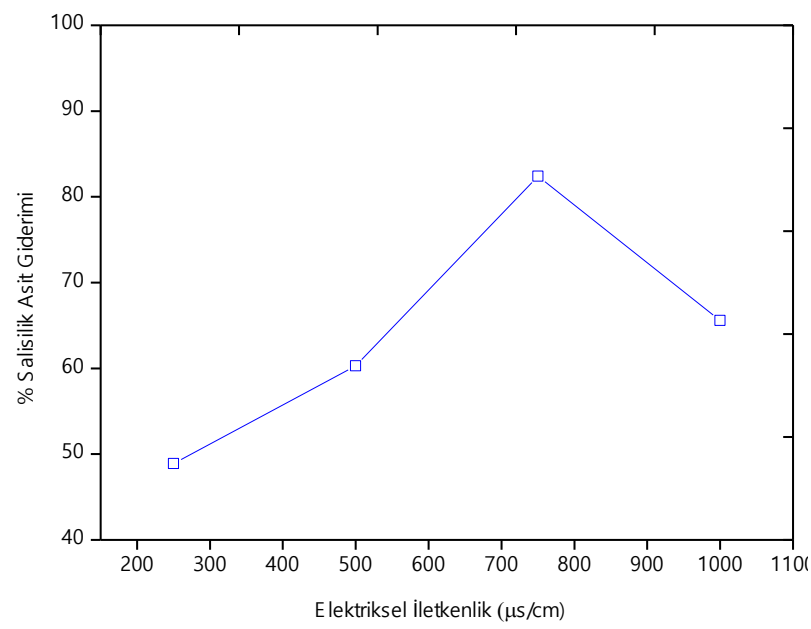

Şekil 9. Farklı Elektriksel İletkenlik değerlerinde SA giderme verimi. (Başlangıç $\mathrm{pH}$ 6, Akım yoğunluğu 80 $\mathrm{A} / \mathrm{m}^{2}$, SA konsantrasyonu $100 \mathrm{mg} / \mathrm{L}$, Elektroliz süresi 20 dakika, Al-Fe-Fe-Al, MP-P bağlantı türünde).

Çalışmada destek elektrolit olarak kullanılan $\mathrm{NaCl}$, elektrokoagulasyon prosesinin etkisinin yanı sıra, proses değerlendirilmesinin yapıldığı 50 dakika gibi kısa zaman periyotlarında bile aktif klor türlerinin oluşumunu sağlayarak (Reaksiyon 3) salisilik asidin maksimum oksidasyonuna neden olmuştur [22].

$$
2 \mathrm{Cl}^{-} \rightarrow \mathrm{Cl}_{2(\mathrm{aq})}+2 \mathrm{e}^{-}
$$

Aynı zamanda $\mathrm{NaCl}$, oksidasyon performansı açısından değerlendirildiğinde, KOİ gideriminde de bir miktar etki gösterebilmektedir [23].

\subsection{Salisilik Asit Giderimi Üzerine Elektroliz Süresinin Etkisi}

Elektrokoagulasyon prosesinde elektroliz süresi oluşan metal hidroksit floklarının miktarı açısından önemlidir. Yeterli miktarda hidroksit floklarının oluşması için gerekli optimum sürenin belirlenmesi gerekmektedir. Bu çalışmada 2-50 dakika aralığında Elektroliz süresi değiştirilerek deneyler gerçekleştirilmiştir. Şekil 10'dan görüleceği üzere süre artıkça Eşitlik 1 ve Eşitlik 2 den de hesaplandığı üzere hem işletme maliyeti artmakta hem de verim artışı görülmektedir.

$\mathrm{Bu}$ çalışmada, hibrit elektrotların kullanıldığı EC prosesi ile sulu çözeltilerden SA'ın giderimi araştırılmıştır. $\mathrm{Bu}$ amaçla EC prosesine etki eden parametrelerden başlangıç $\mathrm{pH}$, akım yoğunluğu, Elektriksel iletkenlik ve elektroliz süresinin etkisi araştırılmıştır. Yapılan deneysel çalışma sonucunda en yüksek verimin alındığı SA için optimum şartlar başlangıç $\mathrm{pH} 6$, akım yoğunluğu $80 \mathrm{~A} / \mathrm{m}^{2}$, elektriksel iletkenlik $750 \mu \mathrm{s} / \mathrm{cm}$ ve elektroliz süresi 40 dakika olarak bulunmuştur. Optimum işletme şartlarında SA verimleri \% 91.4 olarak elde edilmiştir. Bu koşullardaki işletme maliyeti ise $1.34 \$ / \mathrm{m}^{3}$ olarak hesaplanmıştır. Sonuç olarak Al ve Fe elektrotlarının kullanıldığı çalışmada EC prosesi ile SA gideriminde yüksek SA giderme verimleri elde edilmiştir.

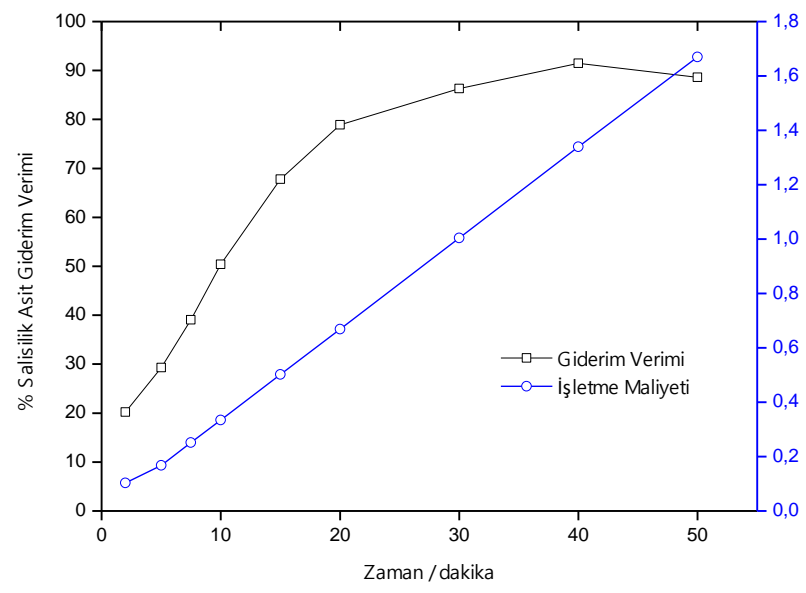

Şekil 10. Farklı Elektroliz sürelerinde SA giderme verimi ve işletme maliyeti. (Başlangıç pH 6, Akım Yoğunluğu 80 $\mathrm{A} / \mathrm{m}^{2}$, SA konsantrasyonu $100 \mathrm{mg} / \mathrm{L}$, elektriksel iletkenlik $750 \mu \mathrm{s} / \mathrm{cm}, \mathrm{Al}-\mathrm{Fe}-\mathrm{Fe}-\mathrm{Al}$, MP-P bağlantı türünde).

Şekil 10'da elektroliz süresine bağlı olarak SA gideriminin ve işletme maliyetlerinin değişimleri görülebilmektedir. Uygulanan elektriksel akıma bağlı olarak işletme maliyeti de lineer bir artış göstermektedir. 50 dakikalık elektroliz süresinde yaklaşık olarak $1.7 \$ / \mathrm{m}^{3}$ lük bir işletme maliyeti oluşmakla birlikte yaklaşık olarak $\% 88$ 'lik bir SA giderim verimine ulaşıllmıştır. Ancak giderim 
verimleri ve işletme maliyetleri birlikte göz önüne alındığında 40. dakikada daha makul sonuçlar elde edilebileceği anlaşılmaktadır.

Şekil 11'de ise elektroliz süresi ile KOİ giderimi ilişkisi verilmekle birlikte aynı zamanda elektroliz sonunda çözelti $\mathrm{pH}$ değerleri görülebilmektedir.

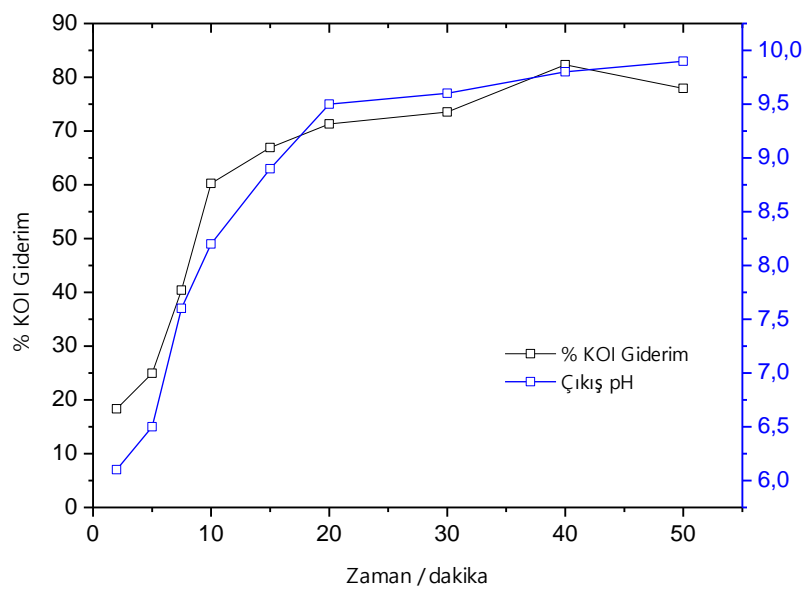

Şekil 11. Farklı Elektroliz sürelerinde KOİ giderim

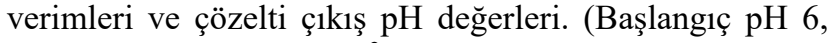
Akım Yoğunluğu $80 \mathrm{~A} / \mathrm{m}^{2}$, SA konsantrasyonu $100 \mathrm{mg} / \mathrm{L}$, elektriksel iletkenlik $750 \mu \mathrm{s} / \mathrm{cm}, \quad \mathrm{Al}-\mathrm{Fe}-\mathrm{Fe}-\mathrm{Al}, \quad \mathrm{MP}-\mathrm{P}$ bağlantı türünde).

Elektroliz süresinin artmasıly birlikte KOİ gideriminin belirli bir süreye kadar artış gösterdiği ve 40 dakikalık elektroliz süresinden sonra ise KOİ giderim veriminin bir platoya ulaştığı görülebilir (Şekil 11). Diğer taraftan katot reaksiyonları gereğince (Eşitlik 2) ortamda $\mathrm{OH}^{-}$iyonlarının varlığına bağlı olarak $\mathrm{pH}$ değerlerinin de artış gösterdiği görülmektedir. Başlangıç $\mathrm{pH}$ değeri 6 olan çözelti 50 dakikalık elektroliz süresi sonrasında $\mathrm{pH} 10$ düzeylerine ulaşmıştır.

Elektrolitik reaktörde üretilen $\mathrm{OH}^{-i y o n l a r ı ~ i l e ~ a s i d i k ~}$ ortamda hafif $\mathrm{pH}$ artması gerçekleşir veya çözelti bazik hale gelebilir. Bu iyonlar hem de alüminyum hidroksit formlarını oluşturur. Yapılan çalışmalarda EC prosesi için en uygun $\mathrm{pH}$ aralığının 5-8 aralığında olduğu yani hafif nötral yada nötür pH'larda oluşan $\mathrm{Al}(\mathrm{OH})_{3}$ floklarının yüksek kirletici giderimde etkili olduğu belirtilmiştir [2].

Sekil 12'de optimum koșullarda uygulanan elektrokoagulasyon işleminde zamana bağlı olarak absorbans azalışı verilmektedir. Şekil 12'ye bakıldığında elektrokoagulasyon işleminin 50 dakikasından sonra neredeyse salisilik asidin tamamen yok olduğu anlaşlabilmektedir.

Çalışmada absorbans azalması mineralizasyon göstergesi olarak seçilmiş olup, arıtma sürecinin her bir kademesinde numune UV bölgede tarama yapılarak mineralizasyon değerlendirmesi yapılmıştır. Böylelikle SA'nın giderim verimi değerlendirilmiştir.

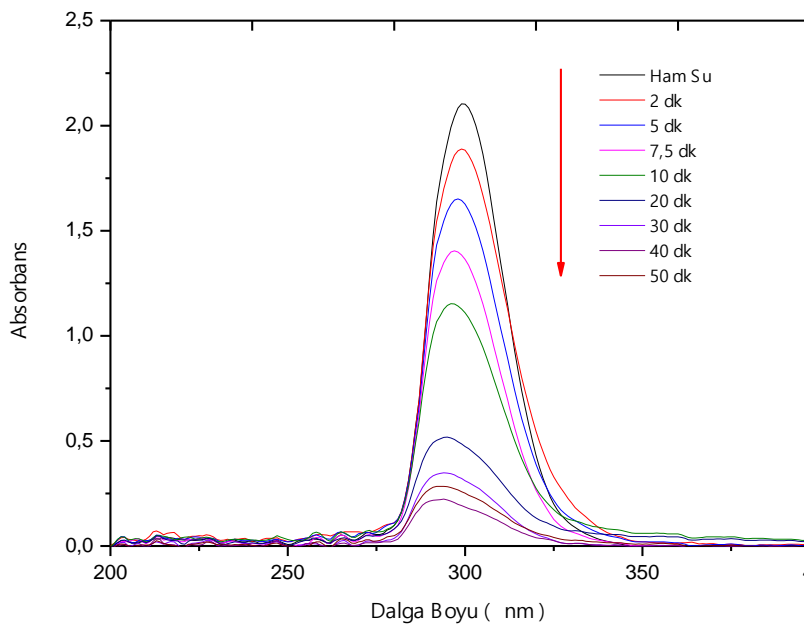

Şekil 12. Optimum koşullarda SA için elektroliz süresine bağlı absorbans azalması (Başlangıç pH 6, Akım Yoğunluğu $80 \mathrm{~A} / \mathrm{m}^{2}$, SA konsantrasyonu $100 \mathrm{mg} / \mathrm{L}$, elektriksel iletkenlik $750 \mu \mathrm{s} / \mathrm{cm}, \quad \mathrm{Al}-\mathrm{Fe}-\mathrm{Fe}-\mathrm{Al}, \quad \mathrm{MP}-\mathrm{P}$ bağlantı türünde).

200-400 nm arasında gerçekleştirilen bu absorbans taramaları salisilik asidin elektrokimyasal olarak bozunması şeklinde açıklanabilmektedir. Ayrıca, 250 - $300 \mathrm{~nm}$ arasında görülen pikler, salisilik asit yapısında bulunan aromatik kısımların parçalanması ve salisilik asidin oluşan ara ürünlerine işaret etmektedir [24].

\section{Sonuçlar}

EC prosesinde SA gideriminde kullanılan elektrot tipinin son derece önemli olduğu görülmüştür. Çalışmada demir elektrotlarının alüminyum elektrotları kadar SA gideriminde etkili olmamıştır. Ayrıca hibrit bağlantı modlarında da yani demir ve alüminyum elektrotların birlikte kullanıldığında sadece alüminyum elektrotlarının kullanıldığı deneylerden daha düşük giderim sonuçları elde edilmiştir. Sonuç olarak alüminyum elektrotlarla $\mathrm{SA}$ gideriminde demir elektrotlardan daha yüksek giderme verimi elde edilmiştir. $\mathrm{Bu}$ durum EC prosesi esnasında oluşan $\mathrm{Al}(\mathrm{OH})_{3}$ floklarına, SA bileşenlerinin adsorbsiyonun $\mathrm{Fe}(\mathrm{OH})_{3}$ floklarına göre daha fazla gerçekleşmesi şeklinde açıklanabilir

Çalışma sonuçlarına göre MP-P elektrot bağlantı türünde optimum deneysel koşullar, $\mathrm{pH} 6,80 \mathrm{~A} / \mathrm{m}^{2}$ akım yoğunluğu, $750 \mu \mathrm{s} / \mathrm{cm}$ elektriksel iletkenlik, 20 dakikalık elektroliz süresi olarak bulunmuştur. Optimum işletme şartlarında SA verimleri \% 91.4 olarak elde edilmiştir. Çalışma kapsamında yürütülen maliyet analizi sonuçlarına göre ise optimum şartlarda $1.34 \$ / \mathrm{m}^{3}$ lük bir arıtma maliyeti hesaplanmaktadır. Sonuç olarak Al ve Fe elektrotlarının kullanıldığı çalışmada EC prosesi ile SA gideriminde yüksek SA giderme verimleri elde edilmiştir.

Diğer taraftan KOİ açısından sonuçlar değerlendirildiğinde ise giderim verimleri yüksek olmakla birlikte belirli bir noktadan itibaren deneysel koşulların giderim verimini daha fazla arttırmadığı göze çarpmaktadır. Önemli ölçüde çözünmüş KOİ'ye sahip olan SA çözeltisinin EC gibi fizikokimyasal bir yöntemle partiküler KOİ'de oldukça iyi sonuçlar sağlamasına rağmen çözünmüş KOİ 
giderimi noktasında sınırlı bir etkiye sahip olduğu söylenilebilir.

Optimum işletme şartlarında oluşan çamur miktarı 0.8 $\mathrm{kg} / \mathrm{m}^{3}$ olarak bulunmuştur. EC prosesi çamur oluşumu bakımından konvansiyonel yöntemlere göre daha düşük çamur üretim miktarlarına sahip olmakla birlikte ortaya çıkan çamurun bertarafi konusunda dikkat edilmesi gerekir. Arıtma süreci sonrasında oluşan çamur mikrokirletici açısından daha yoğun bir içeriğe sahip olmasından dolayı çevresel anlamda risk oluşturmaktadır. $\mathrm{Bu}$ özellikteki çamurun yakma tesislerinde bertarafı uygun bir alternatif olarak görülmektedir.

Çalışmadan elde edilen sonuçlar doğrultusunda farklı ilaç kalıntı maddelerinin veya metabolitlerinin EC prosesi ile gideriminin araştırılmasının yararlı olacağı önerilmektedir.

\section{Çıkar çatışması}

Yazarlar çıkar çatışması olmadığını beyan etmektedir.

\section{Benzerlik oranı (iThenticate): \%14}

\section{Kaynaklar}

[1] G. Sönmez, M. Işık, Sulardaki ilaç kalıntılarının ileri oksidasyon yöntemleri ile giderimi. Turkish Journal of Scientific Reviews, 6, 68-73, 2013.

[2] S. Aksoy, Elektrokoagülasyon prosesi ile sulu çözeltilerden salisilik asit giderimi. Çevre Mühendisliğ ABD, Cumhuriyet Üniversitesi Fen Bilimleri Enstitüsü, Sivas, 2016.

[3] A. H. Dökmeci, Bazı farmasötik ilaç kalıntılarının sulardaki toksik etkileri, (2009).

[4] İ. E. İ. Sendikası, Türkiye İlaç Pazarı, 2020.

[5] W. H. Tsai, T. C. Huang, H. H. Chen, J.-J. Huang, M.H. Hsue, H. Y. Chuang, and Y. W. Wu, Determination of tetracyclines in surface water and milk by the magnesium hydroxide coprecipitation method. Journal of chromatography A, 1217, 415-418, 2010. https://doi.org/10.1016/j.chroma.2009.12.006.

[6] S. O'Connor, and D. S. Aga, Analysis of tetracycline antibiotics in soil: advances in extraction, clean-up, and quantification. TrAC Trends in Analytical Chemistry, 26, 456-465, 2007. https://doi.org/10.1016/ j.trac.2007.02.007.

[7] R.S. Valverde, M.D.G. García, M.M. Galera, and H.C. Goicoechea, Determination of tetracyclines in surface water by partial least squares using multivariate calibration transfer to correct the effect of solid phase preconcentration in photochemically induced fluorescence signals. Analytica Chimica Acta, 562, 8593, 2006. https://doi.org/10.1016/j.aca.2006 .01.035.

[8] Y. Luo, W. Guo, H.H. Ngo, L.D. Nghiem, F.I. Hai, J. Zhang, S. Liang, and X.C. Wang, A review on the occurrence of micropollutants in the aquatic environment and their fate and removal during wastewater treatment. Science of the total environment, 473, 619-641, 2014. https://doi.org/10.1016/ j.scitotenv.2013.12.065.

[9] M.H. Khan, H. Bae, and J.-Y. Jung, Tetracycline degradation by ozonation in the aqueous phase: proposed degradation intermediates and pathway.
Journal of hazardous materials, 181, 659-665, 2010. https://doi.org/10.1016/j.jhazmat.2010.05.063.

[10] I.R. Bautitz, and R.F.P. Nogueira, Degradation of tetracycline by photo-Fenton process-Solar irradiation and matrix effects. Journal of Photochemistry and Photobiology A: Chemistry, 187, 33-39, 2007. https://doi.org/10.1016/j.jphotochem. 2006.09.009.

[11] Y. Liu, X. Gan, B. Zhou, B. Xiong, J. Li, C. Dong, J. Bai, and W. Cai, Photoelectrocatalytic degradation of tetracycline by highly effective $\mathrm{TiO} 2$ nanopore arrays electrode. Journal of Hazardous Materials, 171, 678683, 2009. https://doi.org/10.1016/j.jhazmat.2009. 06.054

[12] Y.-J. Wang, D.-A. Jia, R.-J. Sun, H.-W. Zhu, and D.M. Zhou, Adsorption and cosorption of tetracycline and copper (II) on montmorillonite as affected by solution pH. Environmental Science \& Technology, 42, 32543259, 2008. https://doi.org/10.1021/es702641a.

[13] C. Reyes, J. Fernandez, J. Freer, M. Mondaca, C. Zaror, S. Malato, and H. Mansilla, Degradation and inactivation of tetracycline by $\mathrm{TiO}_{2}$ photocatalysis. Journal of Photochemistry and Photobiology A: Chemistry, 184, 141-146, 2006. https://doi.org/10.1016/j.jphotochem. 2006.04.007.

[14] D. Avisar, O. Primor, I. Gozlan, and H. Mamane, Sorption of sulfonamides and tetracyclines to montmorillonite clay. Water, Air, \& Soil Pollution, 209, 439-450, (2010). https://doi.org/10.1007/s11270009-0212-8.

[15] S. Mondal, M.K. Purkait, and S. De, Advances in dye removal technologie., Springer, 2018. https://doi.org/10.1007/978-981-10-6293-3.

[16] A. Romanov, M. Kobya, and A. Dimoglo, Atıksulardaki kolloidal partiküllerin elektroflotakoagülasyonla giderimi, in: ITÜ 7 . Endüstriyel Kirlenme Kontrolü Sempozyumu, İstanbul, 2000, pp. 67-74.

[17] F. Özyonar, Ö. Gökkuş, and M. Sabuni, Removal of disperse and reactive dyes from aqueous solutions using ultrasound-assisted electrocoagulation. Chemosphere, 127325, 2020. https://doi.org/10.1016/j .chemosphere.2020.127325.

[18] R. Sridhar, V. Sivakumar, V.P. Immanuel, and J.P. Maran, Treatment of pulp and paper industry bleaching effluent by electrocoagulant process. Journal of Hazardous Materials, 186, 1495-1502, 2011. https://doi.org/10.1016/j.jhazmat.2010.12.028.

[19] M.Y.A. Mollah, R. Schennach, J.R. Parga, and D.L. Cocke, Electrocoagulation (EC)-science and applications. J. Hazard. Mater., 84, 29-41, 2001. https://doi.org/ 10.1016/S0304-3894(01)00176-5.

[20] Ö. Gökkuş, and Y.Ş. Yıldız, Application of electrocoagulation for treatment of medical waste sterilization plant wastewater and optimization of the experimental conditions. Clean Technol. Environ. Policy, 17, 1717-1725, 2015. https://doi.org/ 10.1007/s10098-014-0897-2. 
[21] N. Flores, E. Brillas, F. Centellas, R.M. Rodríguez, P.L. Cabot, J.A. Garrido, and I. Sirés, Treatment of olive oil mill wastewater by single electrocoagulation with different electrodes and sequential electrocoagulation/ electrochemical Fenton-based processes. Journal of hazardous materials, 347, 58-66, 2018. https://doi.org/10.1016/j.jhazmat.2017.12.059.

[22] A. Thiam, M. Zhou, E. Brillas, and I. Sirés, A first prepilot system for the combined treatment of dye pollutants by electrocoagulation/EAOPs. Journal of Chemical Technology \& Biotechnology, 89, 11361144, 2014. https://doi.org/10.1002/jctb.4358.
[23] A. Thiam, M. Zhou, E. Brillas, and I. Sirés, Two-step mineralization of Tartrazine solutions: study of parameters and by-products during the coupling of electrocoagulation with electrochemical advanced oxidation processes, Applied Catalysis B: Environmental, 150, 116-125, 2014. https://doi.org/10.1016/j.apcatb.2013.12.011.

[24] F. Ozyonar, H. Muratcobanoglu, and O. Gokkus, Taguchi approach for color removal using electrocoagulation with different electrode connection types, Feb-Fresenius Environmental Bulletin, 7600, 2017 